Asian Pacific Journal of Reproduction

Journal homepage: www.apjr.net

\title{
Effects of long-term exposure to radiofrequency radiations emitted by mobile Jammers on reproduction parameters in rats
}

\author{
Maryam Owjfard ${ }^{2}$, Manzarbanoo Shojaei Fard ${ }^{1,2 \bowtie}$ \\ ${ }^{I}$ Department of Physiology, Fasa University of Medical Sciences, Fasa, Iran \\ ${ }^{2}$ Ionizing and Non-ionizing Radiation Protection Research Center, Shiraz University of Medical Sciences, Shiraz, Iran
}

\section{ARTICLE INFO}

Article history:

Received 15 April 2017

Revision 10 May 2017

Accepted 1 June 2017

Available online 1July 2017

\section{Keywords:}

Radio frequency

Mobile jammers

Testicular

Reproduction

Rats

\begin{abstract}
Objective: To evaluate the effect of long-term exposure to radiofrequency radiations emitted from mobile jammers onrat's reproductive parameters. Methods: Eighty male rats were divided into neonatal group $(n=20)$, immature group $(n=30)$ and mature group $(n=30)$. Neonatal rats were randomly divided into two subgroups. Immature and mature rats were randomly divided into three subgroups. Experimental rats were fixed in the restraining tube and were exposed to radiofrequency radiations emitted from mobile jammers at a distance of $100 \mathrm{~cm}$, for $30 \mathrm{~d}(7 \mathrm{~h} / \mathrm{d})$. Sham group rats were also fixed in restraining tube but without radiations. The control group was allowed to move freely without being exposed to radiation. At the end of the experiment, weight of testes, sperm quality, histological testicular sections and serum testosterone levels were evaluated. Results: Long-term exposure to radiofrequency from mobile jammers could adversely affect neonatal rat fertility, but it did not have significant effects on male mature and immature rat's reproduction parameters. However, restraint stress induced by immobilizing them for a long-period could adversely affect male mature rat's reproductive parameters, but it had no significant effect on male immature rat's reproduction parameters. Conclusion: The effects of EMF exposure to be various based on the life stage.
\end{abstract}

\section{Introduction}

Mobile phone jammers produce radio frequency (RF) which is similar to a mobile phone, usually used to block mobile phone calls, text messages and Wi-Fi internet communications. In some countries, using mobile jammers is legal and they are used in universities to prevent students from cheating or sharing information. in theaters, offices, conference rooms, cinemas, and restaurants to limit the interference caused by the mobile phone users. In most countries, including the U.S., there are strict policies and laws against cell phone jamming devices that prohibit people from possession, selling or operating these devices[1,2].

In modern society, human cannot avoid electromagnetic fields (EMFs) during household and occupational activities, but should be conscious of its biological hazards. Some studies have suggested that exposure to EMF such as mobile phones or wireless internetconnected laptops can have an adverse effect on reproduction and

\footnotetext{
Corresponding author: Manzarbanoo Shojaei Fard, Department of Physiology, Fasa University of Medical Sciences, Fasa, Iran; Ionizing and Non-ionizing Radiation Protection Research Center, Shiraz University of Medical Sciences, Shiraz, Iran.

Tel: +98-9171190566

E-mail: shojaeim@sums.ac.ir
}

fertilizing potential of spermatozoa[3-7].

Infertility could be the result of a combination of factors such as some diseases, genetic problems and life style, or having a job that is in constant exposure to radiation or chemicals, etc. Male infertility is usually caused by problems that affect either sperm generation or sperm motility.

This study aimed toevaluate the effect of long-term exposure to RF radiations emitted from common mobile jammers on testosterone level, semen quality and stereological parameters of testis in male neonatal immature and mature rats.

\section{Materials and methods}

\subsection{Animal treatment}

This experimental study was approved by the Ethics Committee of

This is an open access article distributed under the terms of the Creative Commons Attribution-Non Commercial-Share Alike 3.0 License, which allows others to remix, tweak and buid upon the work non-commercially, as long as the author is credited and the new creations are licensed under the identical terms.

For reprints contact: reprints@medknow.com

(C)2017 Asian Pacific Journal of Reproduction Produced by Wolters Kluwer- Medknow

How to cite this article: Maryam Owjfard, Manzarbanoo Shojaei Fard. Effects of long-term exposure to radiofrequency radiations emitted by common mobile Jammers on reproduction parameters in rats. Asian Pac J Reprod 2017; 6(4): 164-171. 
Shiraz University of Medical Sciences. Eighty male Sprague-Dawley ratswere purchased from the Laboratory Animal Center of Shiraz University of Medical Sciences, Shiraz, Iran. They were housed in room temperature $22-25{ }^{\circ} \mathrm{C}, 12$-h light/dark. Standard lab feed and water was available to animals' ad-libitum. Seven days prior to the study the rats were adapted to lab condition.

Eighty male rats were randomly divided into neonatal (2-5 d, $n=20)$, immature (4-6 wk, weighted 80-120 g, $n=30$ ), and mature (2-3 mo, weighted 180-240 g, $n=30$ ) groups. Neonatal rats were randomly divided into two subgroups of experimental and control.In addition, immature rats were randomly divided into three subgroups, and the same formula was applied to mature rat group of experimental, sham and control groups. Rats in the experimental group were fixed in a rodent restraint device and were exposed to RF radiations emitted from mobile jammer at a distance of $100 \mathrm{~cm}$, for $30 \mathrm{~d}$ (7 h/day). Sham group rats (off condition) were also fixed in a rodent restraint device similar to our experimental group. The control group rats were allowed to move freely in the cages without being exposed to any radiation.

\subsection{Mobile jammer}

In this study, jammer (MB06-Mobile Blocker) was used to work in four different frequency range (global system for mobile communications (GSM), digital cellular service, code division multiple access, third-generation). It was capable of blocking mobile communications within the ranged up to 40 meters[1].

\subsection{Testosterone hormone measurement}

At the end of the experiment, all the subjects were anaesthetized by ether. Blood samples were collected through cardiac puncture, and stored in tubes without anticoagulants and were allowed to clot. After $15 \mathrm{~min}$ of centrifugation ( $2000 \mathrm{r} / \mathrm{min}$, room temperature) to obtain the serum, the serum was stored at $-20{ }^{\circ} \mathrm{C}$ until analysis. Serum testosterone level was evaluated by radio immunoassay technique (DIA source Immuno Assays, S.A.). The kits were purchased from Isotops Ltd, Budapest, Hungary.

\subsection{Epididymis sperm preparation and sperm quality evaluation}

To collect and investigate mature rats semen samples, the epididymis tail was immediately separated and placed in a petri dish containing with $1 \mathrm{~mL}$ pre-warmed phosphate buffered solution. Then they were transferred to an incubator at $37{ }^{\circ} \mathrm{C}$ and gently swirled the petri dish for $10 \mathrm{~min}$ to facilitate the release of sperm. To evaluate spermatozoa motility, semen samples were assessed under light microscopy in randomly 10 selected fields with a $40 \times$ magnification. The sperm motility was assessed based on WHO criteria into three categories, progressive motile, sluggish and immotile sperms. The number of both progressive motile and sluggish sperms was considered as motile. The mean sperm counts were determined via microscopic examination. The semen samples were diluted at 1:10 and then a drop was transferred to the Improved
Neubauer hemocytometer chamber and covered with a cover glass. Then, sperms were counted in one of the large squares within the central counting area of the chamber. Furthermore, sperm viability was evaluated by using eosin-nigrosin staining. Fraction of each sperm suspensions were mixed with an equal volume of $0.5 \%$ eosinnigrosin solution and smeared on a glass microscope slide. Finally, they were assessed with light microscopy in randomly 10 selected microscopic fields for the percentage of vital (unstained) and dead (stained) spermatozoa.

\subsection{Morphometric analysis}

A digital weighing scale (Acculab ALC210.4) was used to weigh the right testes of mature rats. To evaluate morphometric analysis, right testes of all the groups were separated and fixed in (10\%) fresh bufferedformalin. Every testis was sampled for five vertical sections from the equatorial regions. Ethanol and xylene were used for dehydration step. After that, each sample was routinely embedded in paraffin wax, sectioned at thicknesses of $5 \mu \mathrm{m}$ and stained with hematoxylin and eosin (H\&E). Finally our indices were evaluated by a light microscope[10].

Spermatids were monitored and calculated in ten circular-transverse sections of testicular tubules. Total, lumen and cellular diameters $(\mu \mathrm{m})$, lumen, cellular and cross sectional area $\left(\times 10^{4} \mu \mathrm{m}^{2}\right)$, number of tubules (per $0.5 \mathrm{~mm}^{2} \times 0.5 \mathrm{~mm}^{2}$ ), and numerical density were determined in 10 circular transverse sections in different region of testis[8-10].

The mean seminiferous tubule diameter (D) was derived by taking the average of two diameters, D1 and D2 at right angles. Crosssectional area (Ac) of the seminiferous tubules was determined using the equation $\mathrm{Ac}=\pi(\mathrm{D} / 2)^{2}$, where $\pi$ is equal to 3.14 and $\mathrm{D}$, the mean diameter of seminiferous tubules. The number of profiles of seminiferous tubules per unit area (NA) (Figure 1) was determined using the unbiased counting frame proposed by Gundersen[11].

Numerical density (Nv) of seminiferous tubules was the number of profiles per unit volume and it used the modified Floderus equation: $\mathrm{Nv}=\mathrm{NA} /(\mathrm{D}+\mathrm{T})$, where NA is the number of profiles per unit area, $\mathrm{D}$ is the mean diameter of the seminiferous tubule and $\mathrm{T}$, the mean thickness of the section $(\mu \mathrm{m})[12]$. The number of spermatids in 10 tubules per testis of allthe groups was calculated.

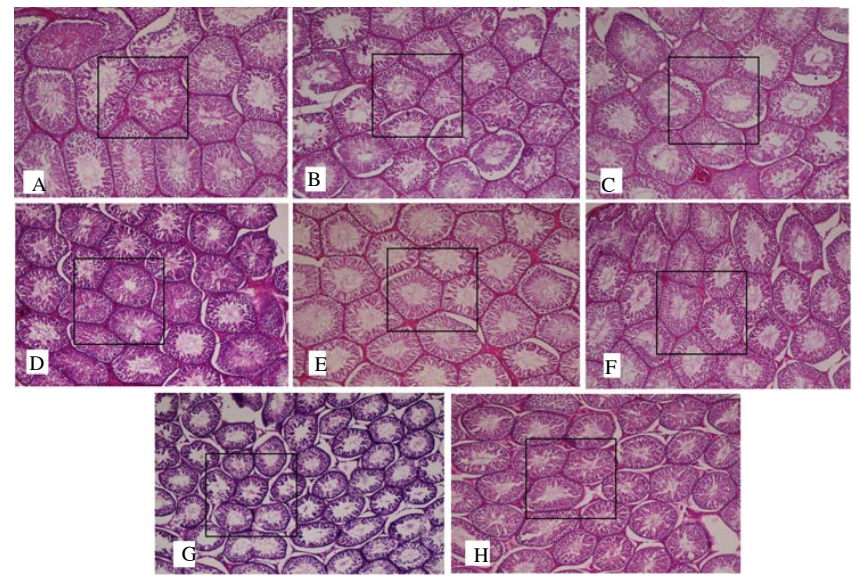

Figure 1. Profiles of seminiferous tubules in mature rats.

A: experimental, B: sham, and C: control groups. Immature rats D: experimental, E: sham, and F: control groups. Neonatal rats G: experimental and $\mathrm{H}$ : sham groups. $\mathrm{H} \& \mathrm{E}$ staining, $\times 40$ magnification. 


\subsection{Statistical analysis}

Data were expressed as mean \pm SEM for all parameters in the graphs (GraphPad Prism version 5.01 for Windows, Graph Pad software Inc., San Diego, CA, USA). Mann-Whitney rank sum test and $t$-test (SPSS for Windows, version 11.5, SPSS Inc, Chicago, Illinois)were used to detect the differences between the control and RF radiations exposed rats in the neonatal group. Differences between the control, sham and radiofrequency radiations exposed rats in mature and immature groups were determined by one-way analysis of variance (ANOVA), and Kruskal Wallis followed by Tukey HSD test. A P-value less than 0.05 were considered as significant difference.

\section{Results}

Statistical analyses showed that there were no significant differences in weight gain $(\mathrm{g})$ after the exposure of the neonatal, immature and mature rats to jammer radiation (Figure 2A, B and C). Moreover, the mature rat testis weight $(\mathrm{g})$ was evaluated to be less in the experimental group than in the sham and the control groups ( $P=0.008, P=0.001$, respectively) (Figure 2D).
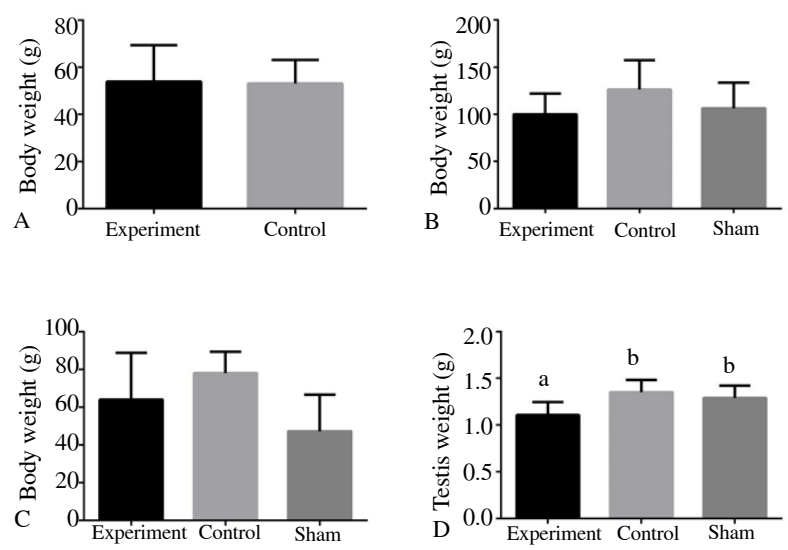

Figure 2. Mean \pm SE of weight gain ( $g$ ) during the experiment period between groups.

A: neonatal, B: immature, and C: mature rats, D: testis weight $(\mathrm{g})$ between mature rat subgroups.

Testes in all the groups showed tubules with thin basement membrane and tunica propria. Moreover, normal germinal epithelium showedan array of spermatogonia, spermatocytes, with groups of spermatids, and mature spermatozoa (Figure 3).

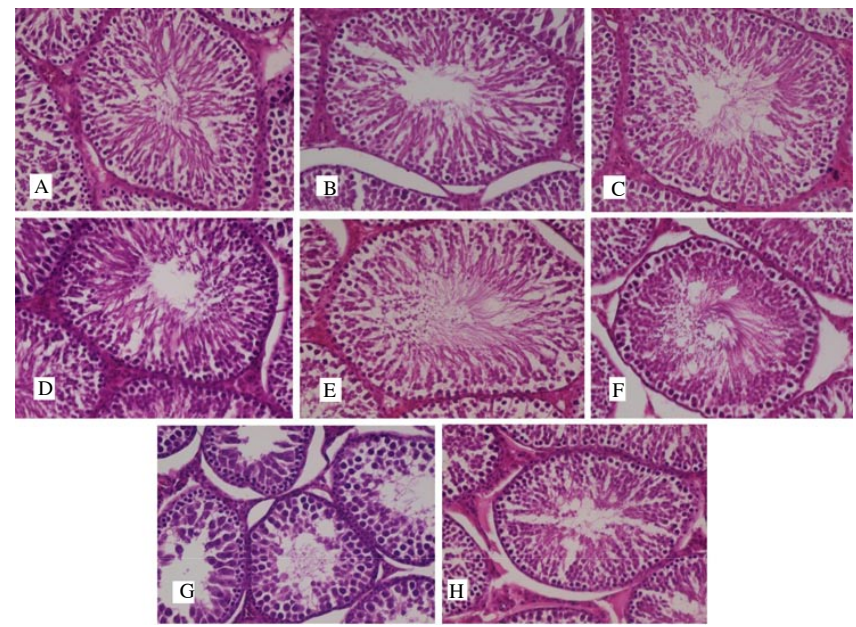

Figure 3. H\&E staining of epididymis from seminiferous tubules in mature rats.

A: experimental, B: sham, and C: control groups. Immature rats D: experimental, E: sham, and F: control groups. Neonatal rats G: experimental and $\mathrm{H}$ : sham groups. $\times 200$ magnification.

In neonatal rats, the luminal diameter $(\mu \mathrm{m})$, germinal epithelium thickness $(\mu \mathrm{m})$, total diameter $(\mu \mathrm{m})$ of the seminiferous tubules showed a significant reduction compared with those in control animals $(P=0.001)$. Besides, luminal area $\left(\times 10^{4} \mu \mathrm{m}^{2}\right)$ and the germinal epithelium area $\left(\times 10^{4} \mu \mathrm{m}^{2}\right)$ of the seminiferous tubules along with the total area of the tubules in cross sectional $\left(\times 10^{4} \mu \mathrm{m}^{2}\right)$ also reduced when the neonatal rats exposed to the jammer radiation compared with those in control rat testis $(P=0.001)$. Statistical analyses also revealed that after treated the neonate rats with jammer radiation, the number of spermatids were less compared with the control group $(P=0.001)$ (Figure 4A, B and C) (Figure 5A, B and C) (Figure 6C). However, the number of seminiferous tubules per unit area (per $0.5 \mathrm{~mm}^{2} \times 0.5 \mathrm{~mm}^{2}$ ) of the testis and numerical density in the experimental group of neonatal rats were more than in the control group $(P=0.001)$ (Figure 6A and $\mathrm{B})$.

In the experimental and sham groups of immature rats, lumen diameter $(\mathrm{mm})$ and area $\left(\times 10^{4} \mathrm{~mm}^{2}\right)$ of the seminiferous tubules were less than the control group $(P=0.001)$ (Figure 4D ) (Figure $5 \mathrm{D})$. Moreover, germinal epithelium thickness $(\mu \mathrm{m})$ and area ( $\times 10^{4} \mathrm{~mm}^{2}$ ) of the seminiferous tubules in the experimental and sham groups showed a significant increase compared with those in the control group $(P=0.001)$ (Figure $4 \mathrm{E})$ (Figure 5E). In addition, numerical density (Figure $6 \mathrm{E}$ ) and the number of the spermatids in the seminiferous tubules was the same $(P>0.05)$ (Figure 6F).

In mature rats, none of the evaluated parameters showed significant difference between experimental and control testis. However, the experimental groups revealed a significant difference with sham groups in parameters such as the germinal epithelium thickness $(\mu \mathrm{m})$ and area $\left(\times 10^{4} \mu \mathrm{m}^{2}\right)$, the total diameter, numerical density and the number of the seminiferous tubules in cross sections $(P=0.015$, $P=0.02, P=0.009, P=0.042, P=0.009$, respectively) (Figure $4 \mathrm{H}, 5 \mathrm{H}$, 

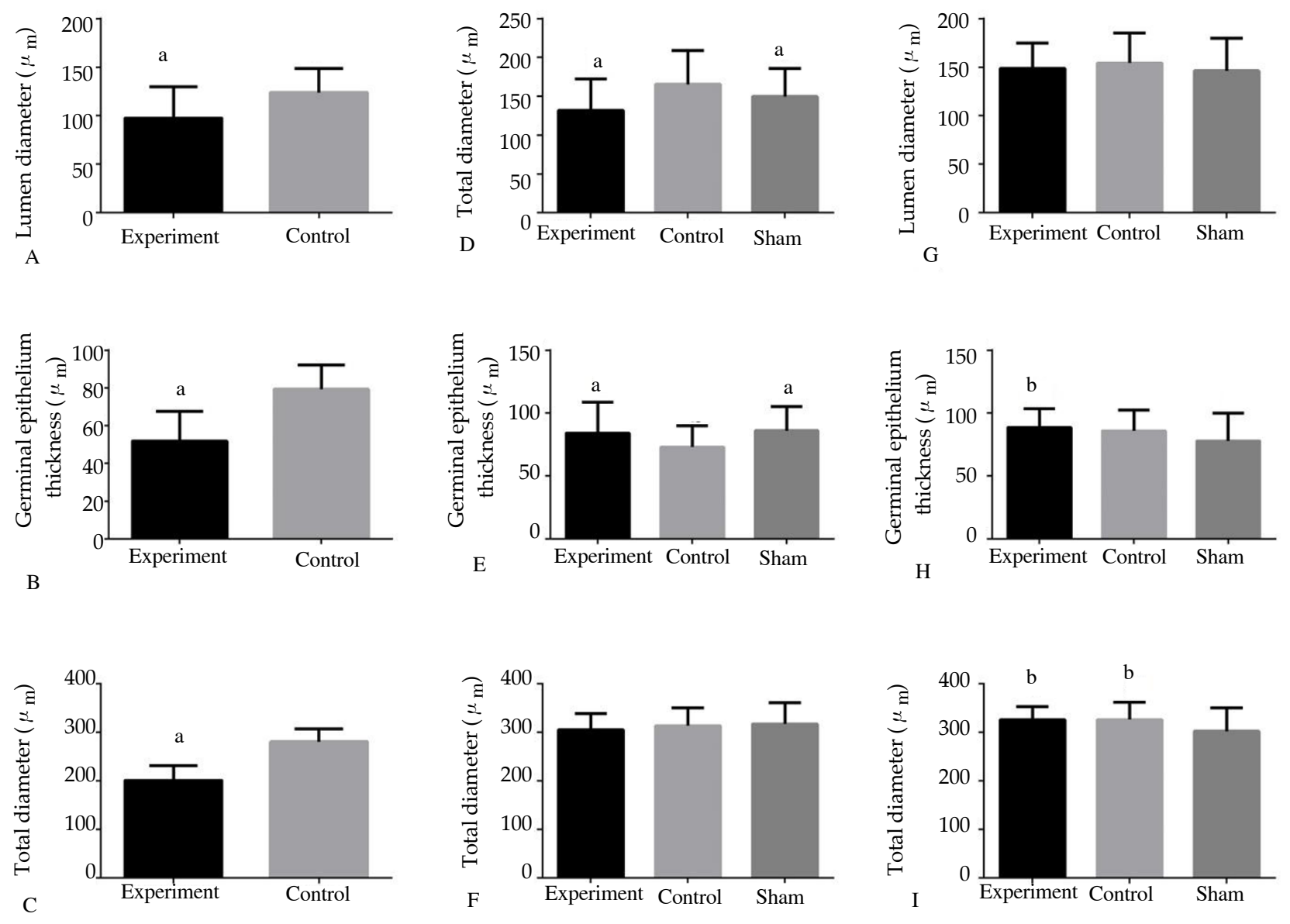

Figure 4. Mean \pm SE for the morphometric indices of seminiferous tubules.

Lumen diameter $(\mu \mathrm{m})$ in A: neonatal, D: immature and G: mature rats. Cellular diameter $(\mu \mathrm{m})$ in B: neonatal, E: immature, H: mature rats, and the total diameter ( $\mu \mathrm{m})$ in C: neonatal, F: immature, I :mature rats.a represents significant differences with control group $(P<0.05)$; b represents significant differences with sham group $(P<0.05)$.

4I and 5I, respectively). Moreover, germinal epithelium thickness and area and also the total diameter, the number of seminiferous tubules per unit area (per $0.5 \mathrm{~mm}^{2} \times 0.5 \mathrm{~mm}^{2}$ ) and numerical density was more in the sham than the control group $(P=0.001$, $P=0.003, P=0.001, P=0.001, P=0.004$ ) (Figure 6G and $\mathrm{H}$ ). However, there were no significant differences in the spermatids number of seminiferous tubules between subgroups $(P<0.05)$ (Figure 6I).

Statistical analyses revealed that the most sperm parameters including count, motility and viability was similar in mature experimental, sham and control groups; however, there were some exceptions. The sperm motility showed a significant reduction in sham compared with control group $(P=0.008)$. Also, it was revealed that the sperm viability decreased significantly in experimental group compared with sham $(P=0.01)$ but not with control (Figure 7A and $\mathrm{C}$ ).

The jammer radiation-treated neonatal rats showed a significant lower level of testosterone compared with control group $(P=0.035)$ (Figure 8A). In immature rats, the experimental conditions had no impact on the level of testosterone $(P=0.05)$ (Figure $8 \mathrm{~B})$. Moreover, in the mature rats, testosterone level of both experimental and control subgroups was more than of sham group $(P=0.002$ and $P=0.001$, respectively) (Figure $8 \mathrm{C}$ ).

\section{Discussion}

In the current study, neonatal rats' long-term exposure to RF radiations emitted from a common mobile jammer decreased seminiferous tubules diameter, spermatids number of the seminiferous tubules, andtestosterone level, whilst, the number of seminiferous tubules per unit area (per $0.5 \mathrm{~mm}^{2} \times 0.5 \mathrm{~mm}^{2}$ ) of testis increased.

In immature rats, long-term exposure to RF radiations emitted from acommon mobile jammer or stressed by being restrainedhad no significant effect on the diameter and spermatids number of the seminiferous tubules and testosterone level.

In mature rats, there were no significant differences in the diameter of seminiferous tubules, testosterone level and sperm quality in the exposed rats when compared with the control group. However, longterm restraint without being exposed to radiations decreased the diameter of the seminiferous tubules, percentage of motile sperm and testosterone level. Furthermore, the sperm viability and number of seminiferous tubules per unit area (per $0.5 \mathrm{~mm}^{2} \times 0.5 \mathrm{~mm}^{2}$ ) of testis increased.

In vitro and in vivo studies, reported the effects of EMF exposure to 

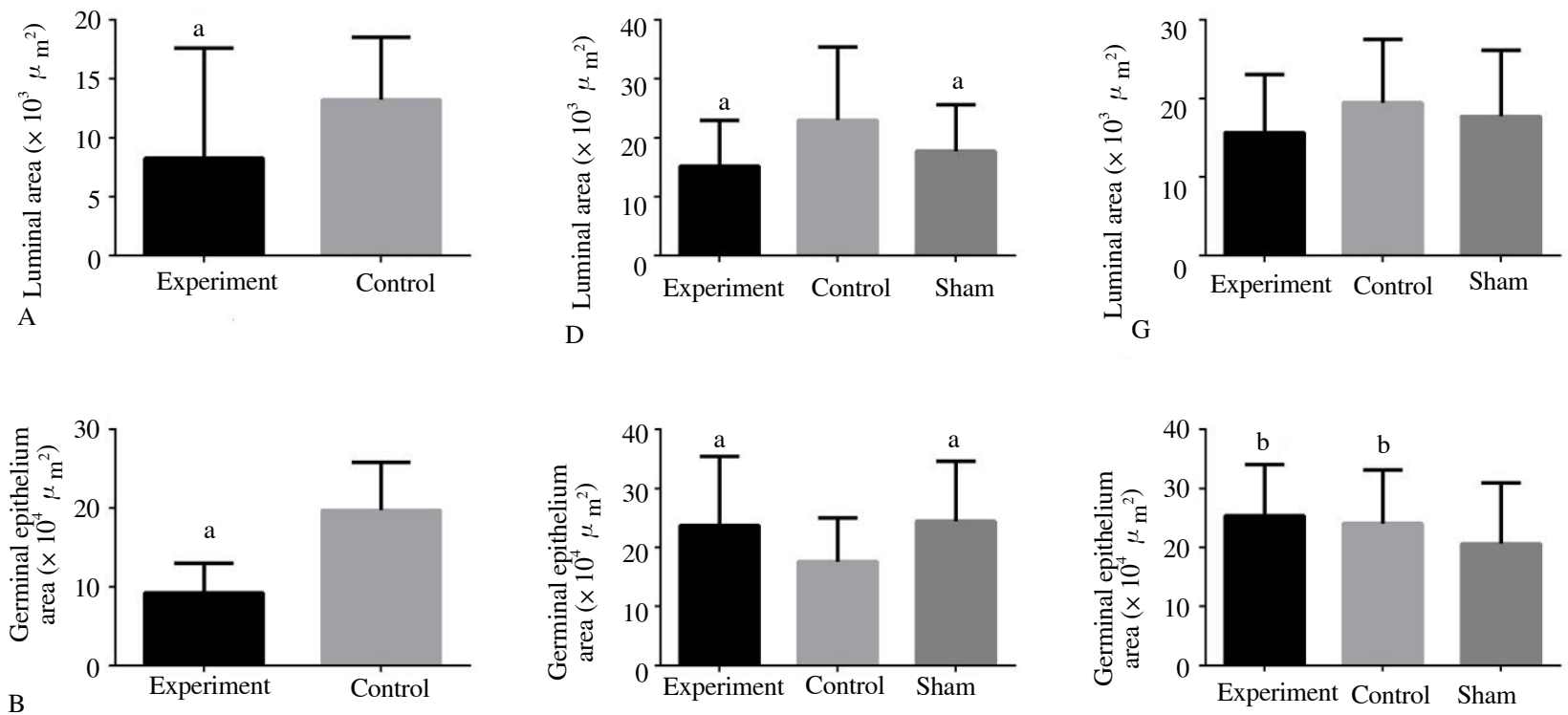

$\mathrm{E}$

$\mathrm{H}$
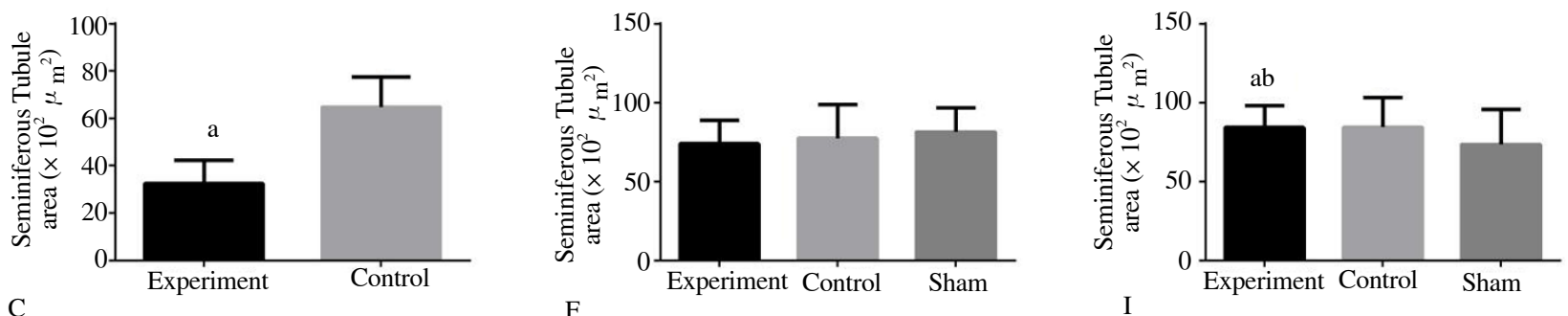

Figure 5. Mean \pm SE for some stereological indices of seminiferous tubules amongst rat groups.

Luminal area $\left(\mu \mathrm{m}^{2}\right)$ in A: neonatal, D: immature, G: mature rats. Cellular area $\left(\mu \mathrm{m}^{2}\right)$ in B: neonatal, E: immature, H: mature rats and cross sectional area of the tubule $\left(\mu \mathrm{m}^{2}\right)$ in C: neonatal, F: immature, and I: mature rats. a represents significant differences with control group $(P<0.05)$; b represents significant differences with sham group $(P<0.05)$; ab showed significant differences with control and sham groups $(P<0.05)$.

be various based on the frequency, exposure period, and the strength of EMF at cellular and organism levels and life stage. For instance, Salama et al.[13] showed that exposure to 800 or $900 \mathrm{MHz}$ GSM RF radiation ( $8 \mathrm{~h} / \mathrm{d}$ for $12 \mathrm{wk}$ ) in standby mode impeded a significant decrease in the diameter of seminiferous tubules in adult rabbits. Furthermore, Bahaodini et al.[7] reported that long-term exposure to low frequency EMF significantly decreased seminiferous tubules diameter and increased the number of seminiferous tubules per unit area of testes[10]. And to $10 \mathrm{~Hz}$ and $1 \mathrm{mT}$ EMF showed a decrease in the tubular diameter, seminiferous tubules area, seminiferous epithelium height, total volume of seminiferous tubule, tubular lumen, seminiferous epithelium in Wistar rats[14]. Being exposed to $10 \mathrm{GHz}$ microwave radiation for $2 \mathrm{~h}$ per day for $45 \mathrm{~d}$ revealed shrinkage in the seminiferous lumen[4]. Exposure to 900-MHz EMF between 13-21 d after pregnancy, showed a decreased diameter in seminiferous tubules and thickness of epithelium in the newborn rats[15]. In addition, Ozguner et al.[16] stated that seminiferous tubules diameter was significantly reduced in adult male rats exposed to EMF. In contrast, Al-Dameghstated that electromagnetic radiation caused a significant enhancement in the diameter of the seminiferous tubules with a disorganized seminiferous tubule sperm cycle interruption of rat[17]. Whereas, RF radiation emitted from cellular phones has no significant effect on testicular function or structure[18]. Additionally, exposure to a mobile phone radiation during pubertal development for $1 \mathrm{~h}$ a day for $45 \mathrm{~d}$ did not have harmful effects on testicular histology in rats[19]. Moreover, Trosic et al.[20] reported no significant effect of the applied RF radiation on testicular function or structure. Saygin et al.[21] indicated no differences in the diameter of the seminiferous tubules in the Wistar rats exposed to $2.45 \mathrm{GHz} \mathrm{EMF}$, for $60 \mathrm{~min} / \mathrm{d}$ for $28 \mathrm{~d}$. Rats exposed to mobile phone radiation for $1 \mathrm{~h} / \mathrm{d}$ for $28 \mathrm{~d}$ showed reduced percentage of motile sperm[10]. Sperm motility in rats exposed to 50 $\mathrm{Hz}$ EMF for $24 \mathrm{~h} / \mathrm{d}$ for $85 \mathrm{~d}$ decreased. On the contrary, EMF did not affect the total sperm concentration and viability. Cell phone waves decreased sperm parameters in human semen samples[22]. Sperm count and motility in Wistar rats decreased as the magnetic field strength increased[7]. Sperm count in rats exposed to EMF in various manner by placing a mobile phone over the cage decreased[23]. 

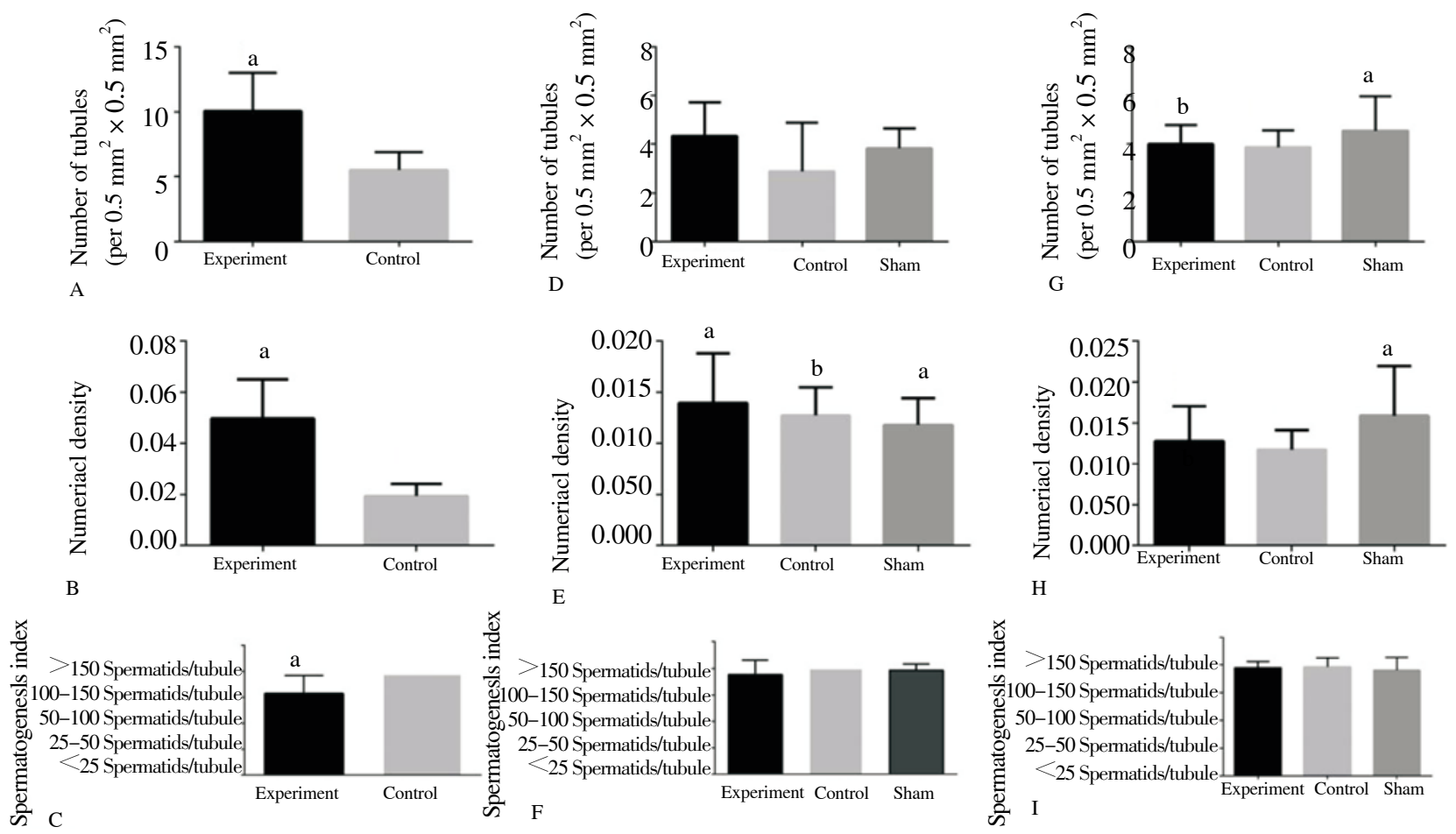

Figure 6. Mean \pm SE for some stereological indices of seminiferous tubules amongst rat groups.

Number of seminiferous tubules (per $0.5 \mathrm{~mm}^{2} \times 0.5 \mathrm{~mm}^{2}$ ) of testis in A neonatal, D immature, G mature rats. Numerical density of the seminiferous tubules in $\mathrm{B}$ neonatal, $\mathrm{E}$ immature, $\mathrm{H}$ mature rats, and the spermatids number of seminiferous tubules in $\mathrm{C}$ neonatal, $\mathrm{F}$ immature, and I mature rats. a represents significant differences with control group $(P<0.05)$; b represents significant differences with sham group $(P<0.05)$.
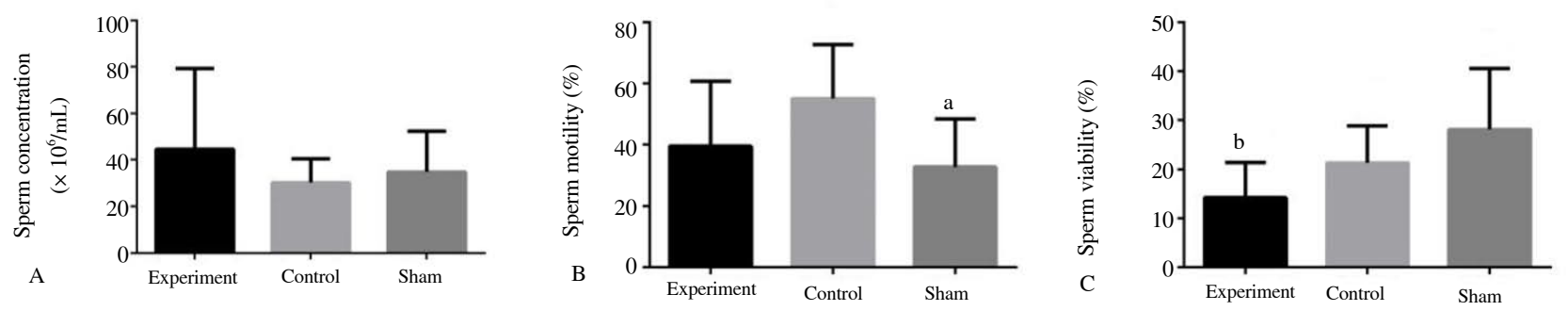

Figure 7. Mean \pm SE for sperm quality evaluation between subgroups in mature rats.

A sperm concentration $\left(\times 10^{6} / \mathrm{mL}\right)$, B percentage of sperm motility, and C Percentage of sperm viability. a represents significant differences with control group $(P<0.05)$; b represents significant differences with sham group $(P<0.05)$.
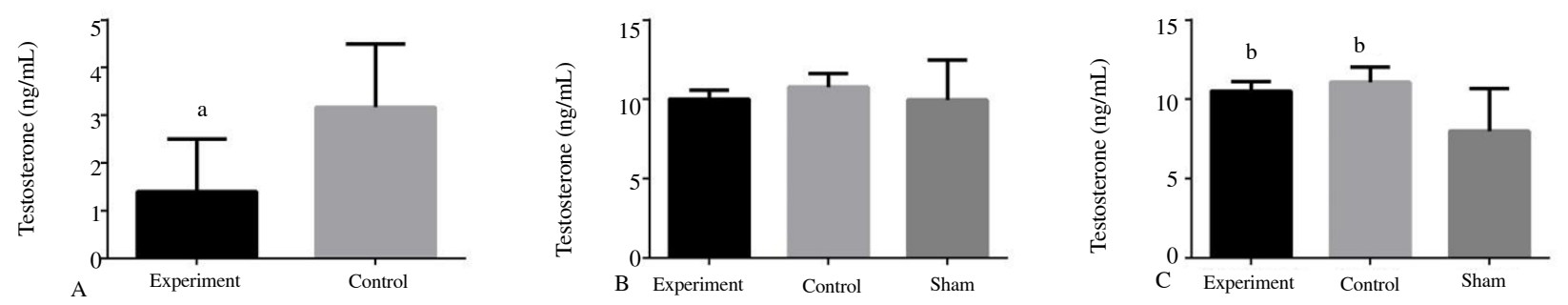

Figure 8. Comparison of Testosterone levels $(\mathrm{ng} / \mathrm{mL})$ between subgroups.

A: neonatal, B: immature, and C: mature rats. a represents significant differences with control group $(P<0.05)$; b represents significant differences with sham group $(P<0.05)$.

Furthermore, magnetic fields created by laptop computers may reduce sperm count and sperm motility in men. Also, sperm count and motility reduced as the magnetic field strength enhanced[1]. Cell phones usage reduced semen quality in men by lowering the sperm count, motility, viability, and normal morphology[5]. Sperm suspension was exposed to an internet-connected laptop by Wi-Fi for $4 \mathrm{~h}$, showed a significant decrease in progressive sperm motility[9]. Odaci et al.[24] reported exposed pregnant rats to $900 \mathrm{MHz}$ EMF for $1 \mathrm{~h}$ each day during day 13-21 of pregnancy had a higher apoptotic index, greater DNA oxidation levels and lower sperm motility and 
vitality compared to the control group[24]. RF radiation exposure from cell phones adversely affects male fertilizing potential of spermatozoa[4]. Microwave exposure may have a significant effect on reproductive system of male rats, which may be a symptom of male infertility[4]. Exposed to an internet-connected laptop by WiFi for $4 \mathrm{~h}$ decreased significantly sperm motility[9]. The prolonged use of cell phones may have negative effects on the human sperm motility and morphology[25]. Exposure to electromagnetic field through cell phones reduced in the human semen quality; including sperm motility and morphology but, does not affect the total sperm count[6]. The spermatozoa in both experimental animals and humans exposed to RF electromagnetic radiation for the longest time periods decreased motility, concentration, and viability[26]. In contrast to our results, exposure to EMF did not induce any adverse effects on the reproductive capacity including sperm quantity, quality, and morphology[20,27].

About $50 \mathrm{~Hz}$ sinusoidal magnetic field decreased testosterone levels of adult male rats significantly only after 6 and $12 \mathrm{wk}$ of the exposure period[27]. Exposure to $900 \mathrm{MHz}$ radiofrequency electromagnetic field decreased testosterone level of male SpragueDawley rat[28]. Long-term exposure to mobile phone radiation leads to reduce in serum testosterone levels. Exposed to $30 \mathrm{~min}$ per day, 5 $\mathrm{d} / \mathrm{wk}$ for 4 wk to $900 \mathrm{MHz}$ EMF causes significant decrease in serum total testosterone level[16]. Exposure to static magnetic field (128 $\mathrm{mT} ; 1 \mathrm{~h} / \mathrm{d}$ for $30 \mathrm{~d}$ ) decreased rat testosterone levels[29]. Exposure to mobile phone radiation $60 \mathrm{~min} / \mathrm{d}$ for $3 \mathrm{mo}$ significantly decrease the serum testosterone level of Wistar rats[28]. Exposed to $10 \mathrm{GHz}$ microwave radiation for $2 \mathrm{~h} /$ day for $45 \mathrm{~d}$ significantly decreases the testosterone level of seventy day-old rats[30]. In spite of, exposure to electromagnetic field 1800 and $900 \mathrm{MHz}$ for $2 \mathrm{~h}$ continuously per day for $90 \mathrm{~d}[31]$ and exposure to $1800 \mathrm{MHz}$ GSM-like[32] caused an enhance in testosterone level. However, exposure to circularly polarized with $50 \mathrm{~Hz}$ magnetic fields continuously for $6 \mathrm{wk}$ in rats[33]; exposure to static magnetic fields $50 \mathrm{~Hz}$ for $40 \mathrm{~min}$ daily for $17 \mathrm{~d}[34]$; and exposure to $50 \mathrm{~Hz}, 5 \mathrm{mT}$ magnetic field for periods of 1,2 and $4 \mathrm{wk}[35]$ have no significant effects on testosterone level of male rats.

Some researches with similar protocols have evaluated the effects of RF radiation exposure on the male reproductive system in the rat, mice, rabbit and human. The results of such studies have shown a decrease in sperm quality (including motility, count, etc.) and testis morphometric parameters. Jammer exposure to rats also induced the same effects that were against or along with the aforementioned studies $[1,2,26]$. These data depend on the duration of using and device distance with the body. The strong documents explain RF radiation at the limitation of specific absorption rate $(0.4-1.6 \& 2.0 \mathrm{~W} / \mathrm{Kg})$ have no thermal actions, but have non-thermal effects such as production of oxidative stress, shortage of antioxidant enzymes in cell membrane, changes in phosphorylation status and protein express level. Enhances the generation of ROS lead to reduction of motility and cell viability[36,37].

Findings of this study indicate that long-term exposure to RF radiations emitted from common mobile jammers could adversely affect neonatal rat fertility. However, it had no significant effect on male mature and immature rat reproduction parameters.Even though restraint stress induced by immobilizing the rats for long-period could adversely affect male mature rat's reproductive parameters, but it had no significant effect on male immature rat reproduction parameters.

\section{Conflict of interest statement}

The authors declare that thay have no conflict of interest.

\section{Acknowledgments}

The authors wish to thank the Research Consultation Center for their invaluable assistance in editing this manuscript.

\section{References}

[1] Mortazavi S, Parsanezhad M, Kazempour M, Ghahramani P, Mortazavi A, Davari M. Male reproductive health under threat: Short term exposure to radiofrequency radiations emitted by common mobile jammers. J Hum Reprod Sci 2013; 6(2): 124-128.

[2] Parsanezhad ME, Mortazavi SMJ, Doohandeh T, Namavar Jahromi B, Mozdarani H, Zarei A, et al. Exposure to radiofrequency radiation emitted from mobile phone jammers adversely affects the quality of human sperm. Int J Rad Res 2017; 15(1).

[3] Wdowiak A, Wdowiak L, Wiktor H. Evaluation of the effect of using mobile phones on male fertility. Ann Agric Environ Med 2007; 14(1): 169172.

[4] Kumar S, Kesari KK, Behari J. The therapeutic effect of a pulsed electromagnetic field on the reproductive patterns of male Wistar rats exposed to a 2.45-GHz microwave field. Clinics (Sao Paulo) 2011; 66(7): $1237-1245$

[5] Agarwal A, Deepinder F, Sharma RK, Ranga G, Li J. Effect of cell phone usage on semen analysis in men attending infertility clinic: An observational study. Fertil Steril 2008; 89(1): 124-128.

[6] Gutschi T, Mohamad Al-Ali B, Shamloul R, Pummer K, Trummer H. Impact of cell phone use on men's semen parameters. Andrologia 2011, 43(5): 312-316. 
[7] Mortazavi SMJ, Tavassoli AR, Ranjbari F, Moammaiee P. Effects of laptop computers' electromagnetic field on sperm quality. J Reprod Infertil 2010; 11(4): 251-258.

[8] Mailankot M, Kunnath AP, Jayalekshmi H, Koduru B, Valsalan R. Radio frequency electromagnetic radiation (RF-EMR) from GSM $(0.9 / 1.8 \mathrm{GHz})$ mobile phones induces oxidative stress and reduces sperm motility in rats. Clinics (Sao Paulo) 2009; 64(6): 561-565.

[9] Avendano C, Mata A, Sanchez Sarmiento CA, Doncel GF. Use of laptop computers connected to internet through Wi-Fi decreases human sperm motility and increases sperm DNA fragmentation. Fertil Steril 2012; 97(1): 39-45.

[10]Bahaodini A, Owjfard M, Tamadon A, Jafari SM. Low frequency electromagnetic fields long-term exposure effects on testicular histology, sperm quality and testosterone levels of male rats. Asian Pac J Reprod 2015; 4(3): 195-200.

[11]Gundersen HJ, Jensen EB. The efficiency of systematic sampling in stereology and its prediction. J Microsc 1987; 147: 229-263.

[12]Gilliland KO, Freel CD, Lane CW, Fowler WC, Costello MJ. Multilamellar bodies as potential scattering particles in human agerelated nuclear cataracts. Mol Vis 2001; 7: 120-130.

[13]Salama N, Kishimoto T, Kanayama HO. Effects of exposure to a mobile phone on testicular function and structure in adult rabbit. Int J Androl 2010; 33(1): 88-94.

[14]Cetkin M, Kizilkan N, Demirel C, Bozdag Z, Erkilic S, Erbagci H. Quantitative changes in testicular structure and function in rat exposed to mobile phone radiation. Andrologia 2017. doi: 10.1111/and.12761.

[15]Hancı H, Odacı E, Kaya H, Aliyazıcıo lu Y, Turan İ, Demir S, et al. The effect of prenatal exposure to $900-\mathrm{MHz}$ electromagnetic field on the 21old-day rat testicle. Reprod Toxicol 2013; 42: 203-209.

[16]Ozguner M, Koyu A, Cesur G, Ural M, Ozguner F, Gokcimen A, et al. Biological and morphological effects on the reproductive organ of rats after exposure to electromagnetic field. Saudi Med J 2005; 26(3): 405 410 .

[17]Al-Damegh MA. Rat testicular impairment induced by electromagnetic radiation from a conventional cellular telephone and the protective effects of the antioxidants vitamins C and E. Clinics (Sao Paulo) 2012; 67(7): 785-792.

[18]Dasdag S, Zulkuf Akdag M, Aksen F, Yilmaz F, Bashan M, Mutlu Dasdag M, et al. Whole body exposure of rats to microwaves emitted from a cell phone does not affect the testes. Bioelectromagnetics 2003; 24(3): 182-188.

[19]Tumkaya L, Kalkan Y, Bas O, Yilmaz A. Mobile phone radiation during pubertal development has no effect on testicular histology in rats. Toxicol Ind Health 2016; 32(2): 328-336.

[20]Trosic I, Matausic-Pisl M, Pavicic I, Marjanovic AM. Histological and cytological examination of rat reproductive tissue after short-time intermittent radiofrequency exposure. Archiv Ind Hygiene Toxicol 2013; 64(4): 513-519.

[21]Saygin M, Caliskan S, Karahan N, Koyu A, Gumral N, Uguz A. Testicular apoptosis and histopathological changes induced by a 2.45 GHz electromagnetic field. Toxicol Ind Health 2011; 27(5): 455-463.
[22]Erogul O, Oztas E, Yildirim I, Kir T, Aydur E, Komesli G, et al. Effects of electromagnetic radiation from a cellular phone on human sperm motility: An in vitro study. Archiv Med Res 2006; 37(7): 840-843.

[23]Singh U. Effect of electromagnetic radiation of mobile phone on sperm count in Albino rats. Int J Sci Res 2017; 5(10). doi: 10.15373/22778179.

[24]Odaci E, Hanci H, Yulug E, Turedi S, Aliyazicioglu Y, Kaya H, et al. Effects of prenatal exposure to a $900 \mathrm{MHz}$ electromagnetic field on 60day-old rat testis and epididymal sperm quality. Biotech Histochem 2016 91(1): 9-19.

[25]Kesari KK, Behari J. Microwave exposure affecting reproductive system in male rats. Appl Biochem Biotechnol 2010; 162(2): 416-428.

[26]La Vignera S, Condorelli RA, Vicari E, D’Agata R, Calogero AE. Effects of the exposure to mobile phones on male reproduction: A review of the literature. J Androl 2012; 33(3): 350-356.

[27]Amara S, Abdelmelek H, Garrel C, Guiraud P, Douki T, Ravanat JL, et al. Effects of subchronic exposure to static magnetic field on testicular function in rats. Archiv Med Res 2006; 37(8): 947-952.

[28]Sepehrimanesh M, Saeb M, Nazifi S, Kazemipour N, Jelodar G, Saeb S. Impact of $900 \mathrm{MHz}$ electromagnetic field exposure on main male reproductive hormone levels: A Rattus norvegicus model. Int J Biometeorol 2014; 58(7): 1657-1663.

[29]Meo SA, Al-Drees AM, Husain S, Khan MM, Imran MB. Effects of mobile phone radiation on serum testosterone in Wistar albino rats. Saudi Med Journal 2010; 31(8): 869-873.

[30]Kumar S, Behari J, Sisodia R. Influence of electromagnetic fields on reproductive system of male rats. Int J Radiation Biol 2013; 89(3): 147 154.

[31]Ozlem Nisbet H, Nisbet C, Akar A, Cevik M, Karayigit MO. Effects of exposure to electromagnetic field $(1.8 / 0.9 \mathrm{GHz})$ on testicular function and structure in growing rats. Res Vet Sci 2012; 93(2): 1001-1005.

[32]Forgacs Z, Kubinyi G, Sinay G, Bakos J, Hudak A, Surjan A, et al Effects of $1800 \mathrm{MHz}$ GSM-like exposure on the gonadal function and hematological parameters of male mice. Magyar Onkologia 2005; 49(2): 149-151.

[33]Kato M, Honma K, Shigemitsu T, Shiga Y. Circularly polarized, sinusoidal, $50 \mathrm{~Hz}$ magnetic field exposure does not influence plasma testosterone levels of rats. Bioelectromagnetics 1994; 15(6): 513-518.

[34]Moghaddam HF, Ahangarpour A, Birgani MT, Shahbazian H, Badavi M. The effect of 17 days exposure to static magnetic fields on the hypothalamic-pituitary-gonadal axis in the male rat. Iran J Pharm Res 2005; 4(3): 161-168.

[35]Moustafa YM, Mostafa RM, Ali FM. Effect of exposure to $50 \mathrm{~Hz}, 5$ $\mathrm{mT}$ esla magnetic field on sex hormone status in male rats. B Pharm Sci 2004; 27(2): 187-191

[36]Leszczynski D, Joenväärä S, Reivinen J, Kuokka R. Non-thermal activation of the hsp27/p38MAPK stress pathway by mobile phone radiation in human endothelial cells: Molecular mechanism for cancerand blood-brain barrier-related effects. Differentiation 2002; 70: 120-129.

[37]De Iuliis GN, Newey RJ, King BV, Aitken RJ. Mobile phone radiation induces reactive oxygen species production and DNA damage in human spermatozoa in vitro. PLoS One 2009; 4: e6446. 